\title{
Meteorological observations of the coastal boundary layer structure at the Bulgarian Black Sea coast
}

\author{
D. Barantiev ${ }^{1}$, M. Novitsky ${ }^{2}$, and E. Batchvarova ${ }^{1,3}$ \\ ${ }^{1}$ National Institute of Meteorology and Hydrology, Bulgarian Academy of Sciences, Sofia, Bulgaria \\ ${ }^{2}$ Research and Production Association "Typhoon" - Obninsk, Russian Federal Service on Hydrometeorology \\ and Environmental Monitoring, Moscow, Russia \\ ${ }^{3}$ Risoe National Laboratory for Sustainable Energy, RISOE DTU, Roskilde, Denmark
}

Received: 7 January 2011 - Revised: 16 August 2011 - Accepted: 29 August 2011 - Published: 15 September 2011

\begin{abstract}
Continuous wind profile and turbulence measurements were initiated in July 2008 at the coastal meteorological observatory of Ahtopol on the Black Sea (south-east Bulgaria) under a Bulgarian-Russian collaborative program. These observations are the start of high resolution atmospheric boundary layer vertical structure climatology at the Bulgarian Black Sea coast using remote sensing technology and turbulence measurements. The potential of the measurement program with respect to this goal is illustrated with examples of sea breeze formation and characteristics during the summer of 2008. The analysis revealed three distinct types of weather conditions: no breeze, breeze with sharp frontal passage and gradually developing breeze. During the sea breeze days, the average wind speed near the ground (from sonic anemometer at $4.5 \mathrm{~m}$ and first layer of sodar at $30-40 \mathrm{~m}$ ) did not exceed 3-4 $\mathrm{m} \mathrm{s}^{-1}$. The onset of breeze circulation was detected based on surface layer measurements of air temperature (platinum sensor and acoustic), wind speed and direction, and turbulence parameters. The sodar measurements revealed the vertical structure of the wind field.
\end{abstract}

\section{Introduction}

As well known, the breeze circulation and the formation of thermal internal boundary layer (TIBL) over land in coastal areas lead to specific meteorological conditions and specific air pollution problems (Batchvarova et al., 1999; Novitzky et al., 1992; Zhong and Takle, 1992). For this reason, conducting detailed meteorological observations in coastal areas is very important issue both from scientific and practical point of view.

During the last two decades of XX century, a number of experimental campaigns were carried out using Doppler wind radars, lidars, sodars, instrumented tall masts, mesoscale networks of ground and aerological stations (Alpert and Rabinovich-Hadar, 2003; Batchvarova et al., 1999; Batchvarova and Gryning, 1998; Wilczak et al., 1991; Zhong and Takle, 1992). The aim of such studies is to provide data for evaluation of mesoscale models performance in coastal areas and to develop further the parameterisations used in them. The variety of physical, geographical and cli-

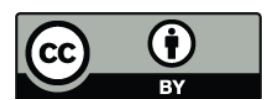

Correspondence to: D. Barantiev

(damyan.barantiev@meteo.bg) mate conditions related to sea breeze circulations, as well as weather patterns in coastal regions is huge (Simpson, 1994), so mesoscale models need to be constantly and vastly evaluated. As noted by Wilczak et al. (1996), the sea breeze is well known and well studied boundary-layer phenomenon, but there still remain issues for investigation about its structure and dynamics, especially in regions of complex or sloping topography.

The present day remote sensing technologies developed robust instruments allowing continuous monitoring and new quality of data for model evaluations. The reliability of these measurements is confirmed by a number of studies devoted to comparisons of remote sensing, tall masts and radiosoundings data (Floors et al., 2011; Novitzky et al., 2010; O'Connor et al., 2010).

In this paper, sodar and ultra sonic anemometer data at a costal site are explored to elucidate the structure of the coastal boundary layer at breeze circulation. Presently, these measurements of turbulence and the vertical wind field structure are unique in Bulgaria. The study area and instruments are presented in Sect. 2; the measurements and analysis - in Sect. 3; and the conclusions - in Sect. 4 of the paper. 


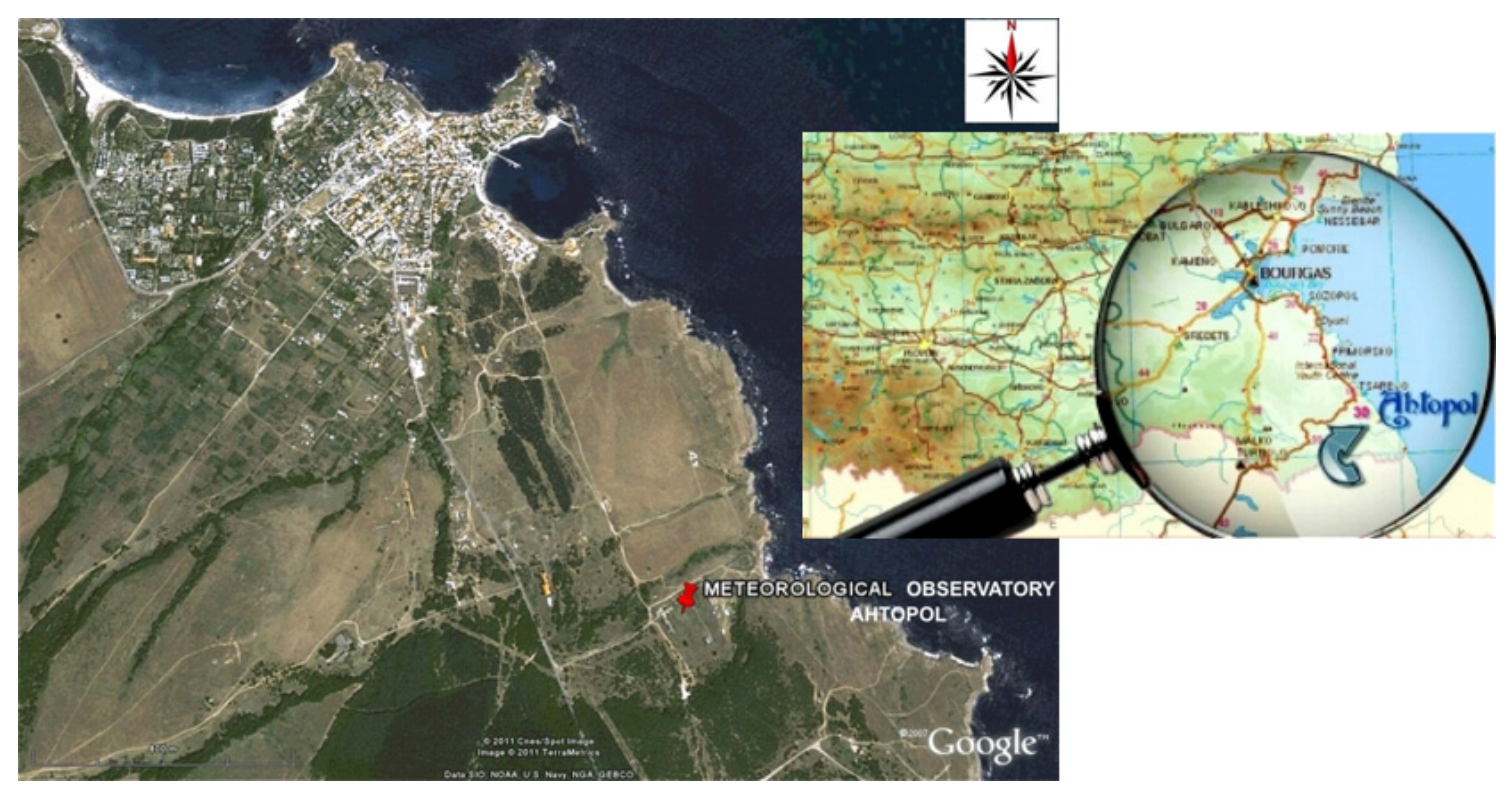

Figure 1. Location of the Meteorological Observatory of Ahtopol (60 km south-east of Burgas) and Google map of the region.

\section{Study area, instruments and data}

The measurements at the meteorological observatory of Ahtopol on the southeast Black Sea coast of Bulgaria (Fig. 1) started on 18 July 2008 under a joint research project between the National Institute of Meteorology and Hydrology - Bulgarian Academy of Sciences (NIMH-BAS) and the Research and Production Association (RPA) "Typhoon" in Obninsk - Russian Federal Service on Hydrometeorology and Environmental Monitoring (Roshydromet). The site is located in flat grassland, $30 \mathrm{~m}$ above sea level, about $500 \mathrm{~m}$ inland from a steep about $10 \mathrm{~m}$ high coast. The coast line is stretching out from north-north-west to south-south-east direction, therefore the winds from the sector $0-150 \mathrm{de}$ grees are representing marine conditions. In the 1970s and 1980s the site was used for the launch of stratospheric rockets. These activities ended in the 1990s and the site was transformed to a meteorological observatory in the system of NIMH.

As shown in Fig. 2 (left) in the present setup, the ultra sonic anemometer and the sensor for solar radiation are mounted on a meteorological mast at height of $4.5 \mathrm{~m}$; and the air temperature and the humidity sensors are installed at $2 \mathrm{~m}$ height within a thermometer screen. These sensors and a global solar radiation sensor form an automatic meteorological station named MK-15. During few days in July 2008, the regular manual measurements at the observatory and MK-15 were compared and showed differences within $0.2 \mathrm{~K}$ for air temperature, $3 \%$ for humidity and $0.2 \mathrm{hPa}$ for pressure. The ultrasonic anemometer is developed by "Typhoon" in Russia; it is produced in limited numbers and is used in the network of Roshydromet. Based on parallel measurements at Obninsk observatory, this instrument (with vertical axis and 3 paths of $125 \mathrm{~mm}$ length at angle 45 degrees from it) is found to give very close results to those of available commercial instruments, Gill Instruments Ltd Wind master, for example (Mazurin and Kolijnikova, 2008; Mazurin et al., 2010). The first prototype of this instrument was used during the International turbulence comparison experiment (ITCE-81), Tsvang et al. (1985). The frequency of measurements of MK-15 is $0.5 \mathrm{~Hz}$ and records are made every $10 \mathrm{~s}$.

The sodar is located on the roof of the administrative building at about $4.5 \mathrm{~m}$ high, Fig. 2 (right panel). It is a Scintec Flat Array middle range instrument (MFAS) with frequency range $1650-2750 \mathrm{~Hz} ; 9$ emission/reception angles $\left(0^{\circ}, \pm 22^{\circ}\right.$, $\pm 29^{\circ}$ ); maximum 100 vertical layers; range between 500 $1000 \mathrm{~m}$; accuracy of horizontal wind speed $0.1-0.3 \mathrm{~m} \mathrm{~s}^{-1}$; range of horizontal wind speed $\pm 50 \mathrm{~m} \mathrm{~s}^{-1}$; accuracy of vertical wind speed $0.03-0.1 \mathrm{~m} \mathrm{~s}^{-1}$; range of vertical wind speed $\pm 10 \mathrm{~m} \mathrm{~s}^{-1}$; accuracy of wind direction 2-3 degrees.

In summer 2008, the sodar is set to measure in regime "optimized pulses for resolution" at 47 levels from 30 to $500 \mathrm{~m}$ with resolution of $10 \mathrm{~m}$. Ten fixed frequencies are emitted sequentially in a standard mode. The averaging time is $20 \mathrm{~min}$ and the records are made every $10 \mathrm{~min}$, thus presenting running 20-min averages.

Concerning data availability, problems with MK-15 occur in winter 2008/2009. Thus data are available for the periods July to October 2008 and from June 2009 onwards.

Apart from electricity shut down problems, the sodar data are available during the days for the entire period since July 2008. During the summers of 2008 and 2009 the night 

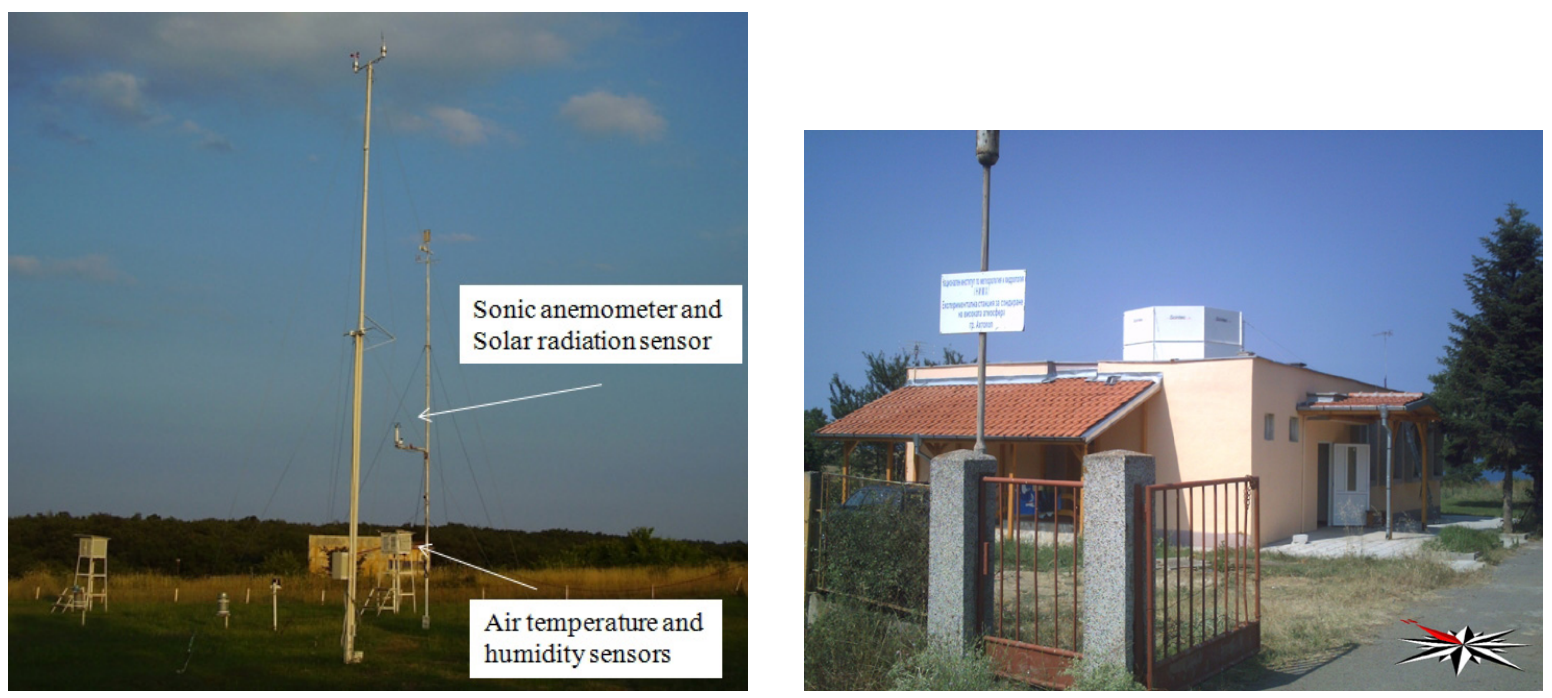

Figure 2. Location of sensors at the meteorological observatory (MO) Ahtopol (left). The SODAR is mounted on the roof of the administration building (right).

operation was suspended. Concerning the period of the present analysis (18 July to 5 September 2008) it can be specified that the sodar was performing measurements from 07:30 until 18:00 in July and August 2008; and from 07:30 until 23:50 in September 2008 in all days except 2 and 3 September. Full diurnal operation and more stable electricity network were achieved since October 2009. The availability of sodar data at different heights was analysed for the period July 2008-June 2009. At $50 \mathrm{~m}$ height, data are available between $83 \%$ of the time in December 2008 and $97 \%$ of the time in May 2009. At $200 \mathrm{~m}$ height, the availability is between 82\% (March 2009) and 96\% (May 2009). In 2010 the performance was more stable.

All measurements included in the analysis are referring to official time, GMT $+3 \mathrm{~h}$ in summer. The Meteorological Observatory Ahtopol is located at $42.08 \mathrm{~N}, 27.95 \mathrm{E}$, and $29 \mathrm{~m}$ above sea level. The local sunrise in August is 18 min earlier compared to Sofia.

\section{Measurements and analysis}

Synoptic analysis shows that the combination of weak high pressure field with warm air mass and clear weather leads to breeze circulation development. The onset of the sea breeze is identified in the records of the mean values and turbulent parameters of all measured meteorological variables. The breeze front passage is expressed in wind direction change, increased wind speed after relatively calm period, increased turbulence parameters (friction velocity, standard deviation of the vertical velocity, standard deviation of the acoustic temperature, sensible heat flux), levelling the air temperature, decrease and/or levelling of relative humidity, decrease of standard deviation of wind direction. In this study, we analyse the summer of 2008, after the start of measurements on 19 July. Data for 2 days with sharp breeze onset, 1 day with gradually developing breeze and 1 day of no breeze are used for illustration.

On 2 August, a small diurnal variation of air temperature (only $3 \mathrm{~K}$ ) was observed. In addition, almost stationary wind speed (2-3 $\mathrm{m} \mathrm{s}^{-1}$ ) and direction (35-40 degrees) were recorded (Fig. 3). No breeze circulation developed on this day. The flow was north easterly (from the sea) during the nights and during the day. A high pressure centre was located north of the Black Sea (Met Office Archive, 2008), Fig. 9a.

On 6 August, the sea breeze was developing gradually because of interaction of large and local scale forcing. The records show sharp increase in temperature between 07:30 and 08:00 a.m. with simultaneous drop in relative humidity, drop in wind speed and change in wind direction by about 90 degrees from 225 to 315 degrees (Fig. 3). This wind direction is from the sea, but the northerly component is due to advection. On that day, a cold front was approaching the Black sea from the Northwest (Met Office Archive, 2008 - Fig. 9c). In the afternoon at about 1 p.m. another abrupt change of wind direction occurs and easterly wind (sea breeze) is established. A reason to consider the day as a type of breeze day is the pronounced land breeze during both nights. A south-westerly wind is observed in the morning probably related to the clear breeze circulation of the previous day and is re-established after 8 p.m. when again south-south-westerly wind was measured. Such gradual change of wind direction clockwise from north through east and south to west is seen often for the Black Sea coast of Bulgaria from synoptic observations and can be associated with the interaction between local and large scale processes. The new observation set up will allow more detailed analysis of such situations. 
(a)

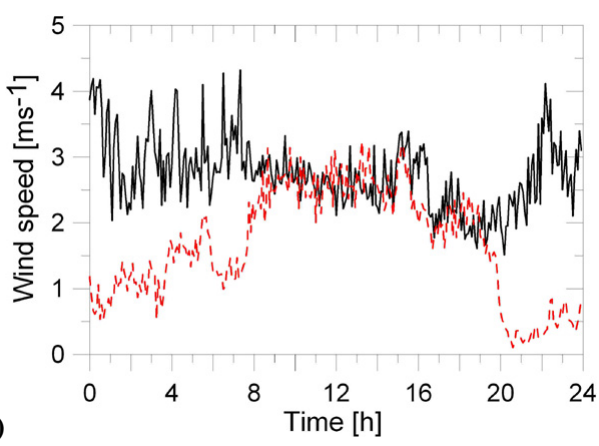

(c)
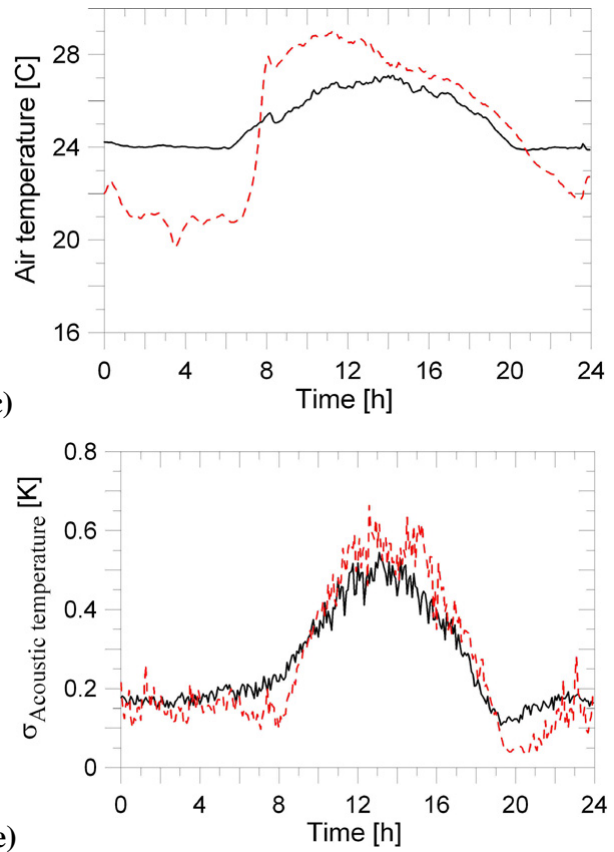

e)

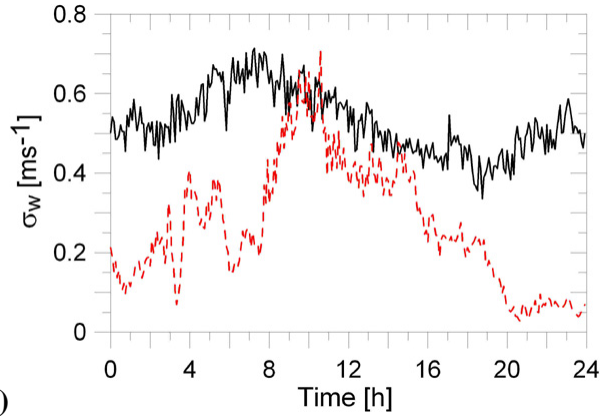

$(\mathrm{g})$

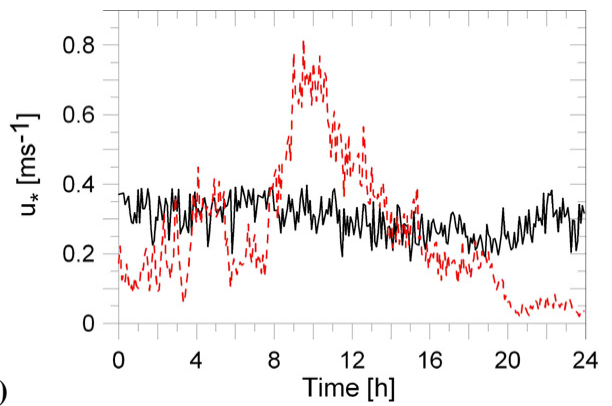

(b)

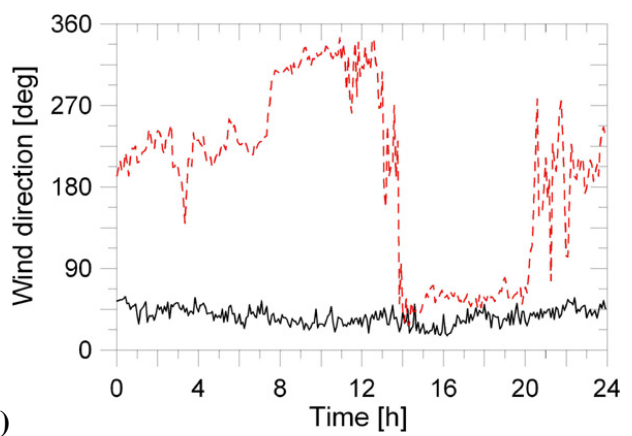

(d)
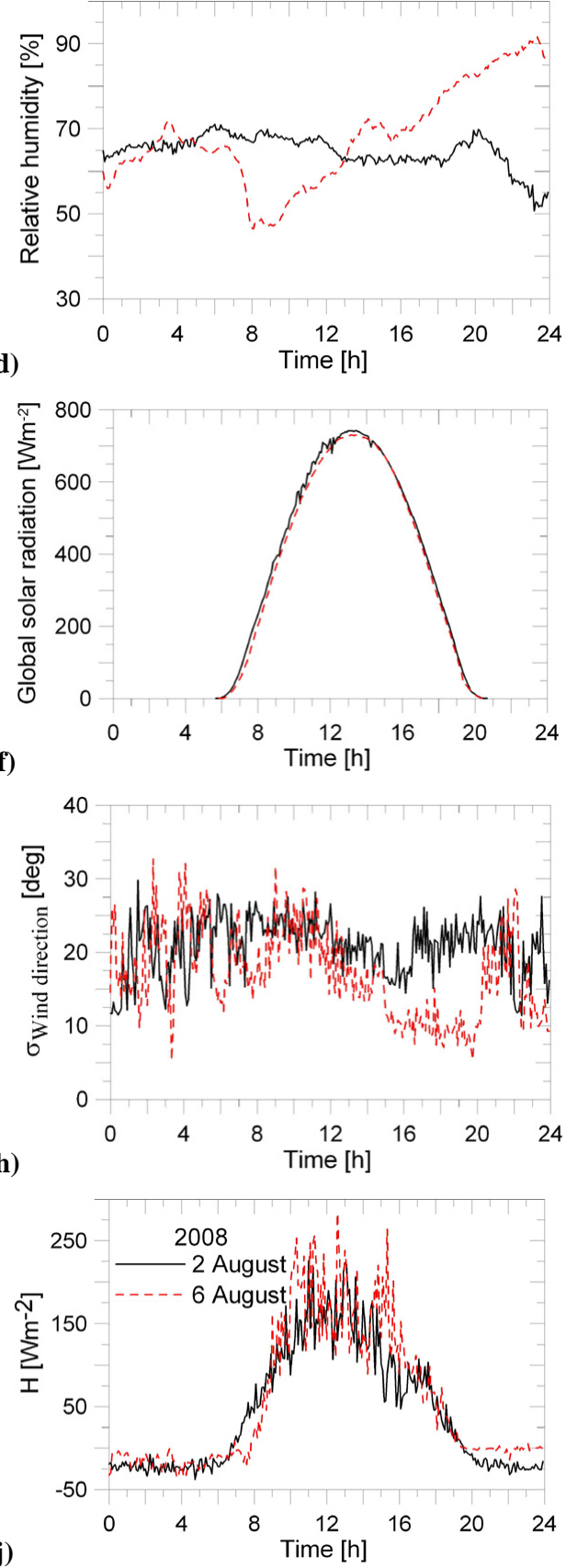

Figure 3. Horizontal wind speed (a); wind direction (b); air temperature (c); relative humidity (d); standard deviation of acoustic temperature (e); global solar radiation (f); standard deviation for the vertical wind speed (g); standard deviation for the wind direction (h); friction velocity (i); and sensible heat flux (j) on 2 August 2008 (black solid lines) and on 6 August (red dashed lines) at MO Ahtopol. Five-minute averaged values. 

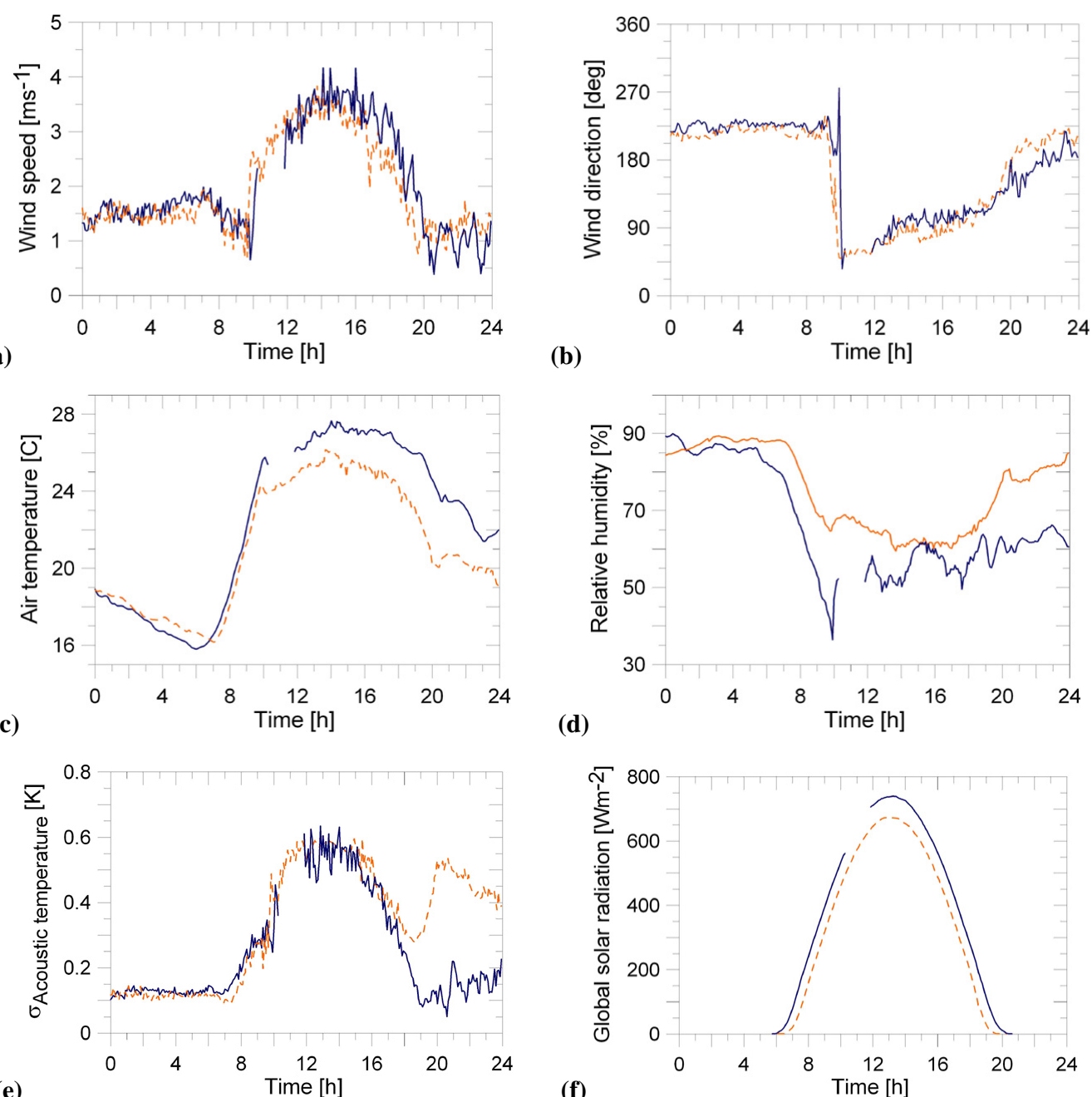

(e)
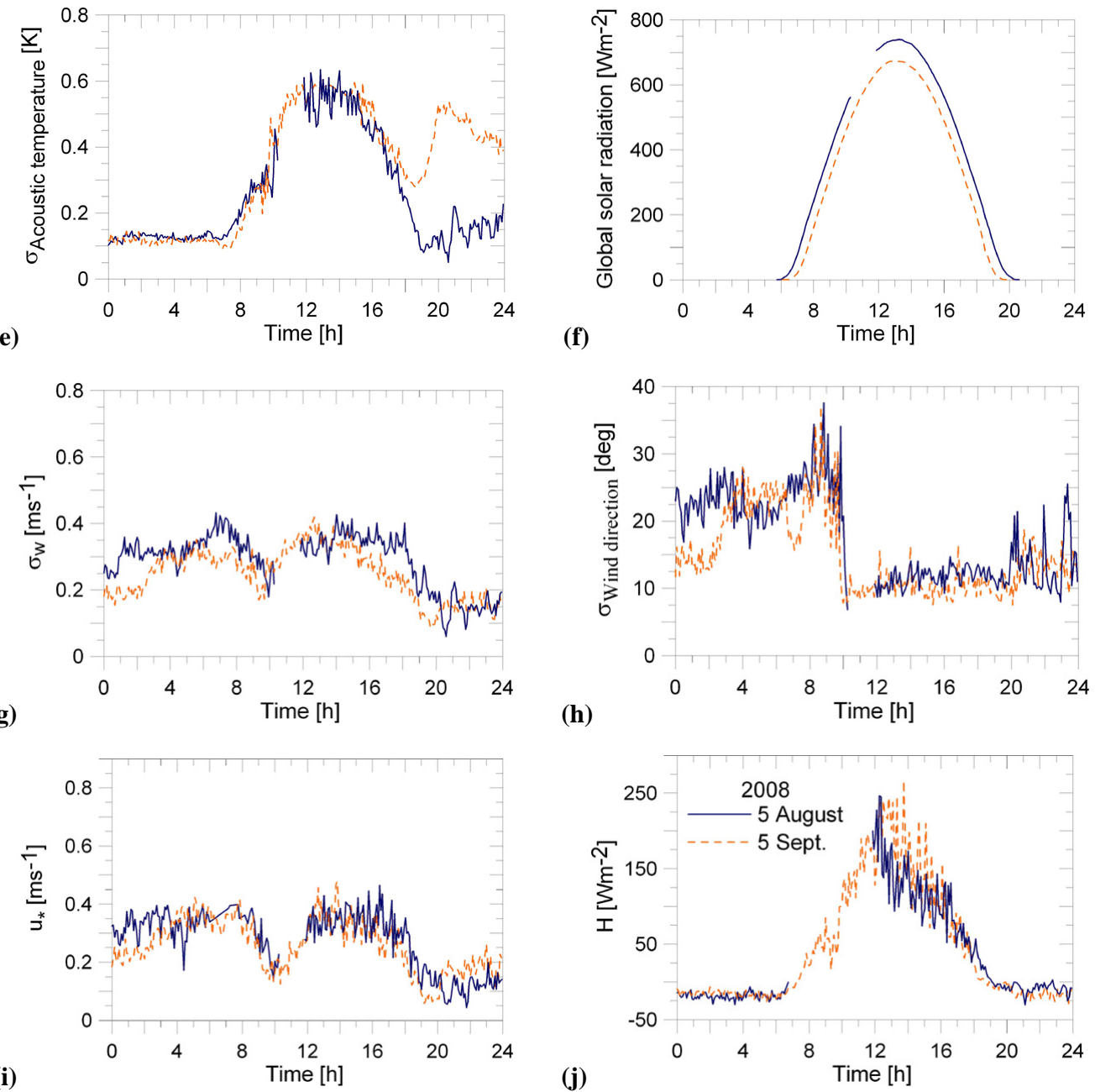

Figure 4. Notation is as in Fig. 3, but for 5 August 2008 (dark blue solid lines) and 5 September 2008 (orange dashed lines). 

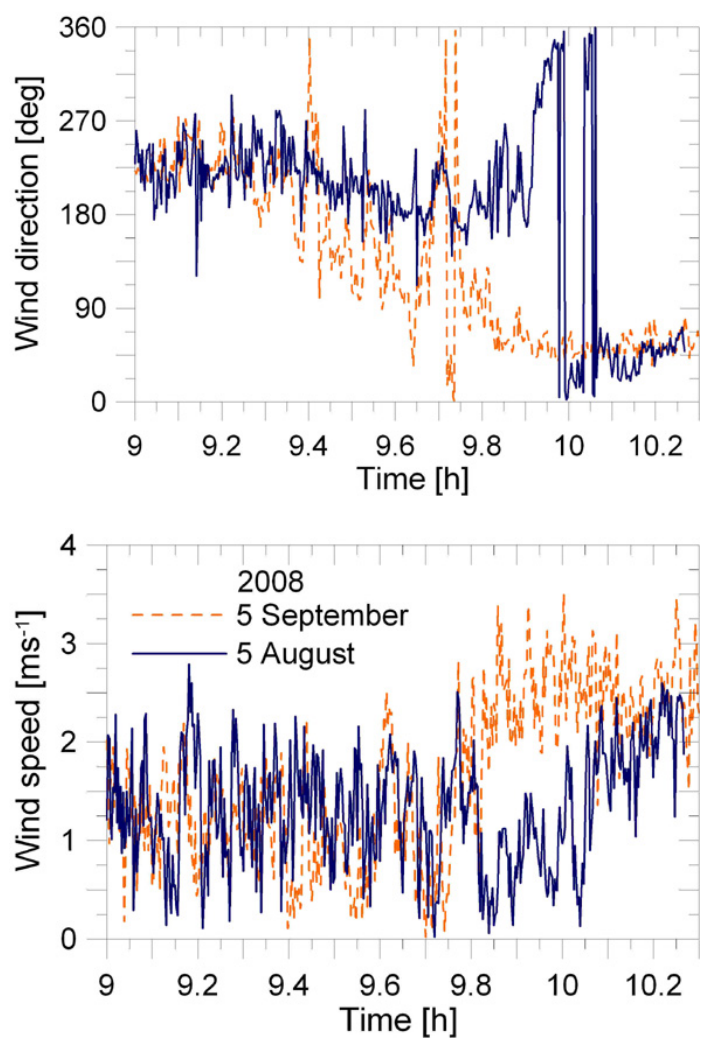

Figure 5. The sharp onset of the sea breeze on 5 August 2008 (dark blue solid lines) and 5 September 2008 (orange dashed lines) in wind direction (upper panel) and wind speed (lower panel) based on the 10-s data.

On 5 August and 5 September, the breeze front passes rapidly resulting in abrupt change in wind direction, wind speed and relative humidity, Fig. 4. The temperature slightly decreases and then levels. The diurnal amplitude for the air temperature is about $12 \mathrm{~K}$ on 5 August and $10 \mathrm{~K}$ on 5 September. The solar radiation is strong reaching above $750 \mathrm{~W} \mathrm{~m}^{-2}$ and the sensible heat flux reaches about $250 \mathrm{~W} \mathrm{~m}^{-2}$, Fig. 4. Especially clear sea breeze front passage is observed on 5 August. At around 10 a.m. a rapid increase in wind speed from $1.5 \mathrm{~m} \mathrm{~s}^{-1}$ to $3.0 \mathrm{~m} \mathrm{~s}^{-1}$ is observed and a sharp turn of wind direction by 180 degrees in less than 10 minutes, Fig. 5. On 5 September the change of wind direction happens within $35-40 \mathrm{~min}$ in two steps. On these days, a change in the values of the turbulence parameters during the sea breeze can be followed. The friction velocity and the standard deviation of the vertical velocity increase after a drop before the front passage. The standard the deviation of the acoustic temperature and the sensible heat flux fluctuate largely during the sea breeze. The standard deviation of wind direction decreases. The synoptic situation on both days is characterized by high pressure conditions and small pressure gradients (Met Office Archive, 2008 - Fig. 9b and d).
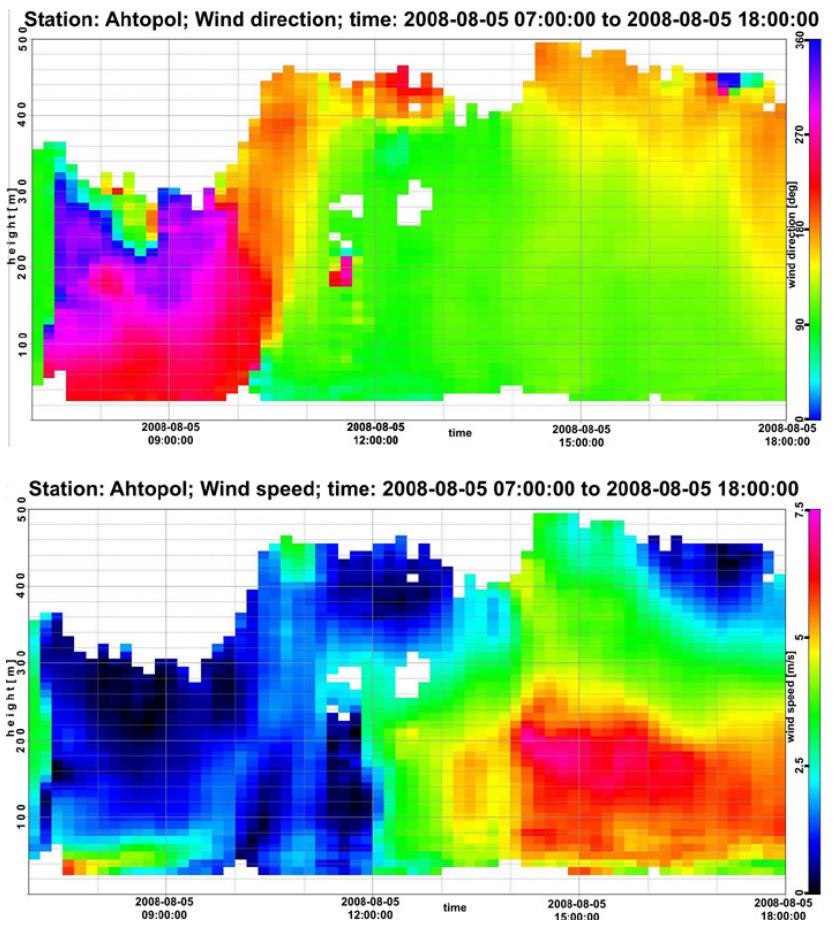

Figure 6. Wind direction (upper panel) and wind speed (lower panel) from sodar at MO Ahtopol on 5 August 2008.

All the parameters shown in Figs. 3 and 4 are calculated as $5 \mathrm{~min}$ averaged values. Partly cloudy conditions in the morning of 2 August are traceable from the small variations of the global radiation before noon.

The soil temperature and the sea water temperature have not been measured at the MO Ahtopol. The closest sea water temperature measurement is performed by NIMH at MO Burgas, $60 \mathrm{~km}$ to the North (Fig. 1), $40 \mathrm{~m}$ offshore using water mercury thermometer at about $30 \mathrm{~cm}$ depth at 09:00, 15:00 and 21:00 local summer time. The sea water temperature record for a period in the beginning of August 2008 was of the range of $25-26^{\circ} \mathrm{C}$ and showed typical diurnal variation $0.6-1.8 \mathrm{~K}$.

Based on surface layer meteorological parameters the onset and characteristics of the breeze circulation can be studied near the ground, but for the vertical extend of the phenomenon, remote sensing technology is required. Sodar backscatter is illustrated here for both days with sharp sea breeze front passage (5 August and 5 September 2008, Figs. 6 and 7) and one day with gradual sea breeze onset (6 August 2008, Fig. 8).

When sharp sea breeze front is observed near the ground, the abrupt change in wind direction happens simultaneously at all levels within a 400-500 m deep layer (Figs. 6 and 7, upper panels). The wind speed is about $2 \mathrm{~m} \mathrm{~s}^{-1}$ and constant with height within the $400 \mathrm{~m}$ layer for about $2 \mathrm{~h}$ after the front passage, but later on stratifies and reaches a maximum of 

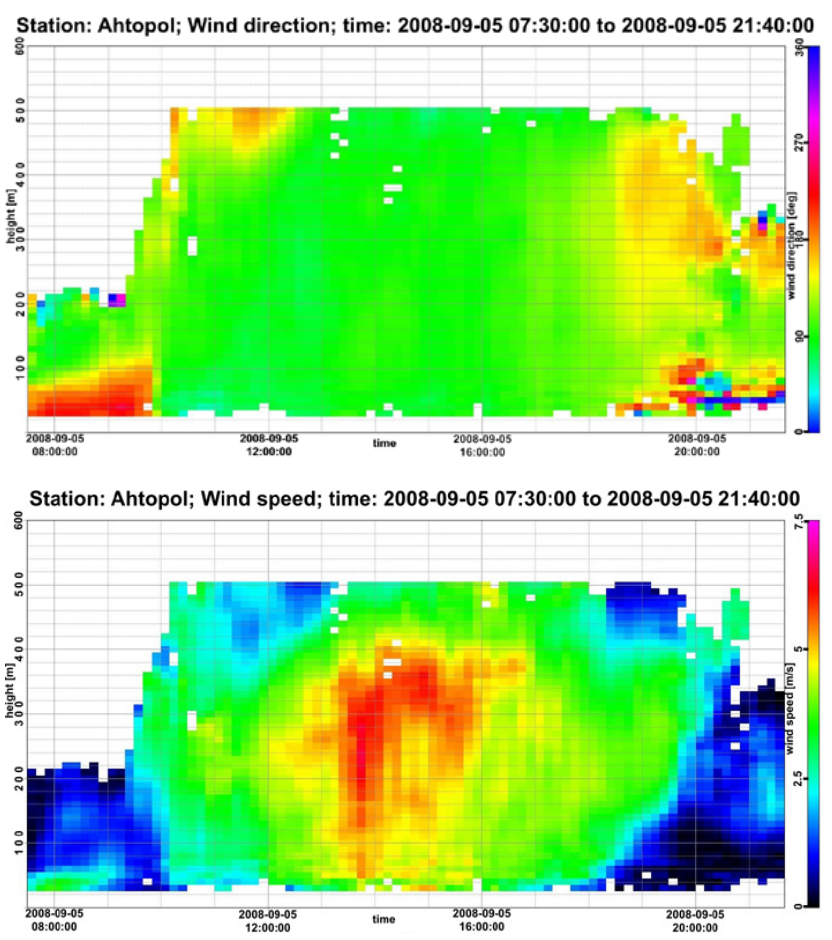

Figure 7. Notation is as in Fig. 6, but for 5 September 2008.
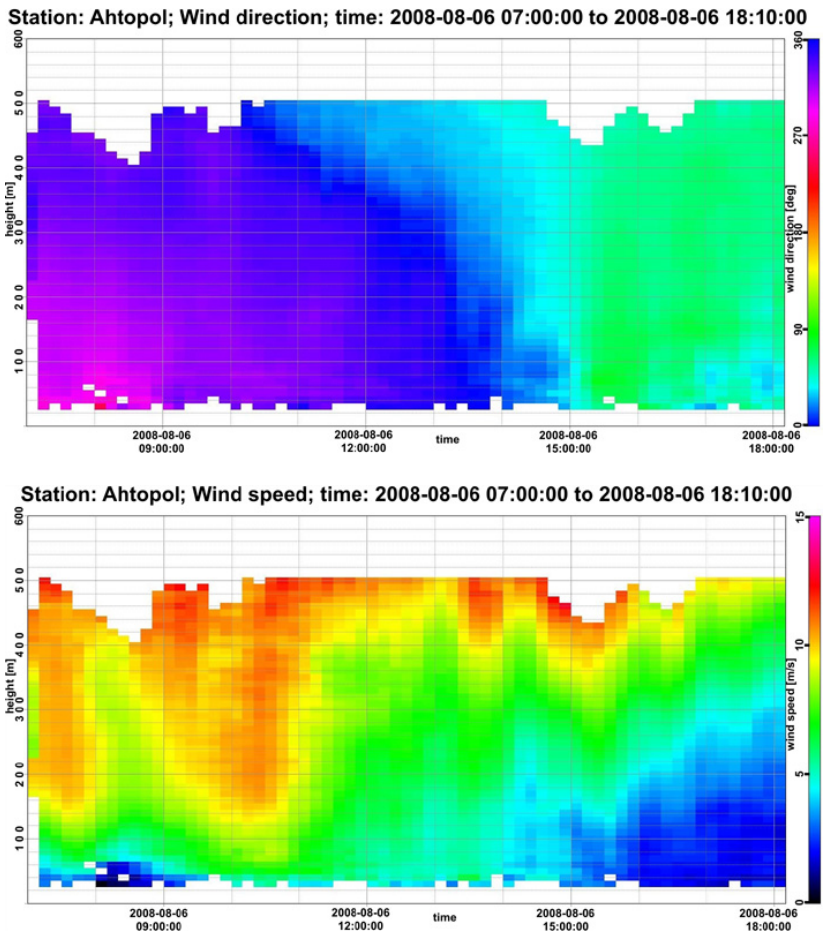

Figure 8. Notation is as in Fig. 6, but for 6 August 2008.
$5-7 \mathrm{~m} \mathrm{~s}^{-1}$ in the layer $50-250 \mathrm{~m}$ on 5 August (Fig. 6, lower panel). On 5 September these features are less pronounced having increase of wind speed with height already at the onset of the sea breeze, reaching 5-7 $\mathrm{m} \mathrm{s}^{-1}$ in a deeper layer 40$420 \mathrm{~m}$ and only between 1 and 4 p.m. (Fig. 7, lower panel).

On 6 August, the westerly flow gradually turns to northerly with height and time from the onset around 8 a.m. until 1 p.m. when a change to easterly flow occurs reaching the entire depth covered by the sodar $(500 \mathrm{~m})$ at 3 p.m. (Fig. 8, upper panel). The wind speed on that day is reaching $10 \mathrm{~m} \mathrm{~s}^{-1}$ at the higher levels (Fig. 8, lower panel).

This analysis shows that on 6 August, a larger scale northerly flow was modified both by the land breeze during the night (early morning westerly flow) and the sea breeze during the day (early afternoon easterly flow). The presence of this large scale flow is also suggested by the synoptic maps (Met Office Archive, 2008 - Fig. 9c). On 5 August and 5 September, no large scale flow was present.

\section{Conclusions}

The data analysis has shown that the combination of remote sensing and eddy correlation measurements is a powerful tool for coastal atmospheric boundary layer studies. With long records of data using the presented instrumental set-up, it will be possible to develop a classification of the sea breeze types at the southern Bulgarian Black Sea coast taking into account the information on turbulence and the vertical structure of the coastal boundary layer. Further, the analysis will continue with comparisons of the measurements with mesoscale models predictions, assessments of sea water temperature from satellite images, introduction of soil measurements. Depending on external funding an extension of the measurements programme is planned to cover several sites in the region and to investigate the penetration of the sea breeze. In addition soil and sea water temperature measurements will be introduced. An important message of this paper is also, that now high quality data are available at a Bulgarian Black Sea coastal site for model validation based on vertical wind profiles.

Acknowledgements. This work is result of intergovernmental agreement for scientific cooperation between Bulgaria and Russia, and in particular it is a part of a research project initiated between the National Institute of Meteorology and Hydrology - Bulgarian Academy of Sciences (NIMH-BAS) and the Research and Production Association (RPA) "Typhoon" - Russian Federal Service on Hydrometeorology and Environmental Monitoring (Roshydromet). The contribution of E. Batchvarova is also supported by the Danish Research Agency Strategic Research Council (Sagsnr. 2104-080025) "Tall wind project" and the EU FP7-People-IEF VSABLA (PIEF-GA-2009-237471). The work is also related to COST Actions ES0702 (EG-CLIMET) and ES1002 (WIRE). 
(a)
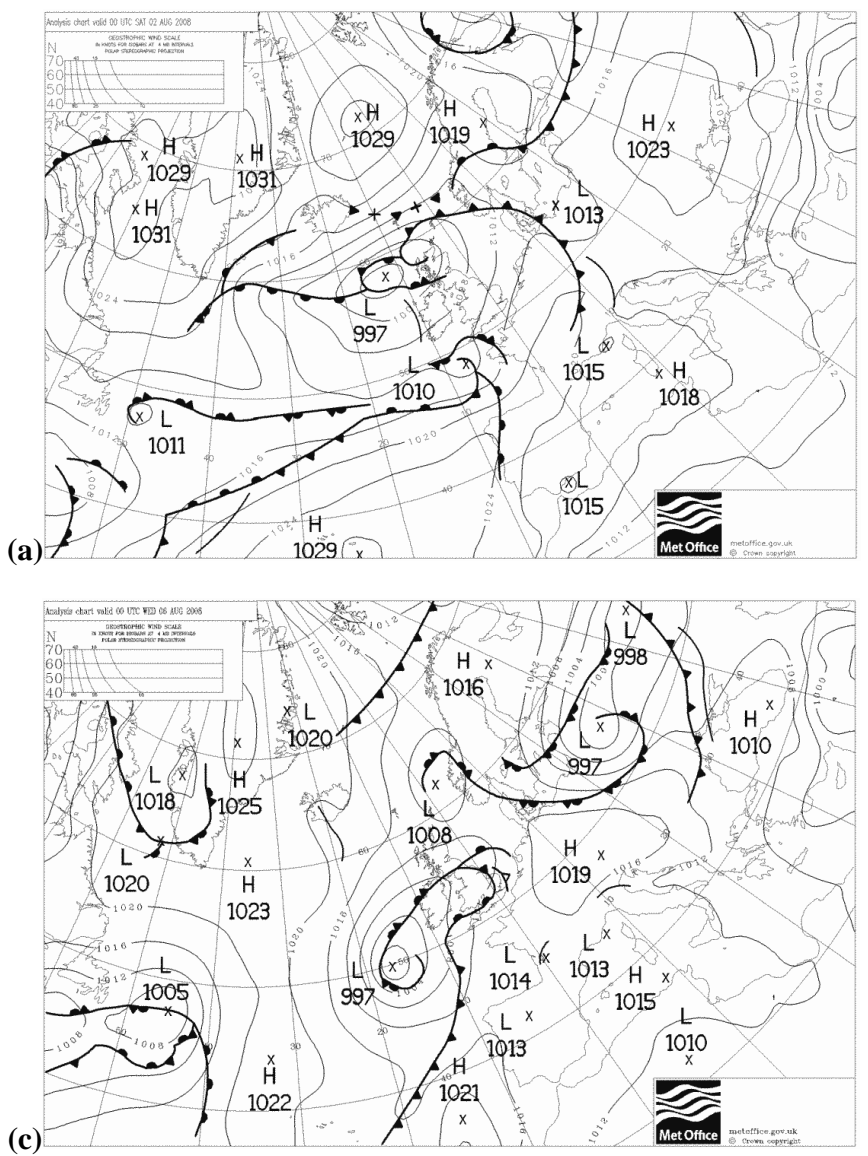

(b)

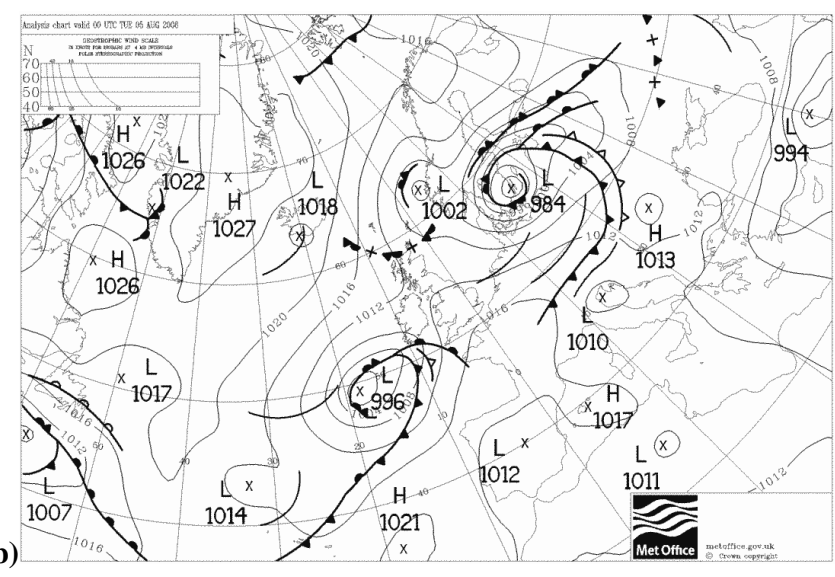

(d)

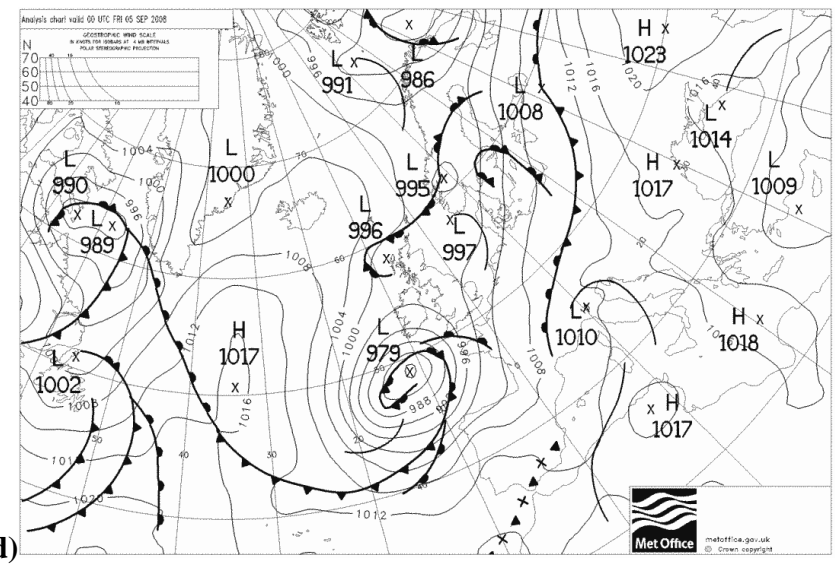

Figure 9. Analysis charts from UK Met Office Archive (2008) at 00:00 UTC on 2 August 2008 (a); 5 August 2008 (b); 6 August 2008 (c) and 5 September 2008 (d).

Edited by: F. Beyrich

Reviewed by: two anonymous referees

SC $\mid \operatorname{nat}^{\mathbf{t}} \begin{aligned} & \text { The publication of this article is sponsored } \\ & \text { by the Swiss Academy of Sciences. }\end{aligned}$

\section{References}

Alpert, P. and Rabinovich-Hadar, M.: Pre- and post-sea-breeze frontal line - a meso- $\gamma$-scale analysis over South Israel, J. Atmos. Sci., 60, 2994-3008, 2003.

Batchvarova, E. and Gryning, S.-E.: Wind climatology, atmospheric turbulence and internal boundary layer development in Athens during the MEDCAPHOT - TRACE experiment, Atmos. Environ., 32, 2055-2069, 1998.

Batchvarova, E., Cai, X., Gryning, S.-E., and Steyn, D.: Modelling internal boundary layer development in a region with complex coastline, Bound.-Lay. Meteorol., 90, 1-20, 1999.

Floors, R., Batchvarova, E., Gryning, S.-E., Hahmann, A. N., Peña, A., and Mikkelsen, T.: Atmospheric boundary layer wind profile at a flat coastal site - wind speed lidar measurements and mesoscale modeling results, Adv. Sci. Res., 6, 155-159, doi:10.5194/asr-6-155-2011, 2011.
Met Office Archive: http://www.wetterzentrale.de/topkarten/ fsfaxsem.html, 2008.

Mazurin, N. F. and Kulijnikova, L. K.: Comparison of instruments used for atmospheric turbulence measurements, Meteorologia i Gydrologia, 11, 90-96, 2008 (in Russian).

Mazurin, N. F., Matzkevich, M. K., Milchenko V. T., and Novitzky, M. A.: Atmospheric surface layer turbulence measurements in urban conditions, Meteorologia i Gydrologia, 6, 38-49, 2010 (in Russian).

Novitsky, M. A., Reible, D. D., and Corripio, B. M.: Modeling the dynamics of the land-sea breeze circulation for air quality modelling, Bound.-Lay. Meteorol., 59, 163-175, 1992.

Novitzky M. A., Mazurin N. F., Kulijnikova, L. K., Tereb L. A., Kalinicheva, O. U., Nechaev, D. R., and Safronov, V. L.: Comparing measured wind and temperature profiles using commercial sodar and tall meteorological mast observations in Obninsk. - Problems of hydrometeorology and environmental monitoring, ISBN 978-5-901579-21-3, 4, 122-136, 2010 (in Russian).

O'Connor, E. J., Illingworth A. J., Brooks, I. M., Westbrook, C. D., Hogan, R. J., Davies, F., and Brooks, B. J.: A method for estimating the turbulent kinetic energy dissipation rate from a vertically pointing Doppler lidar, and independent evaluation from balloon-borne in situ measurements, J. Atmos. Ocean. Technol., 27, 1652-1664, 2010. 
Simpson J. E: Sea breeze and local wind, Cambridge University Press, 234 pp., 1994.

Tsvang, L. R., Zubkovskii, S. L., Kader, B. A., Kallistratova, M. A., Foken T., Gerstmann, V., Przadka, A., Pretel, Ya., Zeleny, Ya., and Keder, J.: Internationa turbulence comparison experiment (ITCE-81), Bound.-Lay. Meteorol., 31, 325-348, 1985.

Wilczak, J. M., Dabberdt, W. F., and Kropfli, R. A.: Observations and numerical model simulations of the atmospheric boundary layer in the Santa Barbara coastal region, J. Appl. Meteorol., 30, 652-673, 1991.
Wilczak, J. M., Gossard, E. E., Neff, W. D., and Eberhard, W. L.: Ground-based remote sensing of the atmospheric boundary layer: 25 years of progress, Bound.-Lay. Meteorol., 78, 321-349, 1996.

Zhong, S. and Takle, E. S.: An observational study of sea- and landbreeze circulation in an area of complex coastal heating, J. Appl. Meteorol., 31, 1426-1438, 1992. 